\title{
Evaluation of the Efficacy of Acaricides Used to Control the Cattle Tick, Rhipicephalus microplus, in Dairy Herds Raised in the Brazilian Southwestern Amazon
}

\author{
Luciana G. Brito, ${ }^{1}$ Fábio S. Barbieri, ${ }^{1}$ Rodrigo B. Rocha, ${ }^{1}$ \\ Márcia C. S. Oliveira, ${ }^{2}$ and Elisana Sales Ribeiro ${ }^{1}$ \\ ${ }^{1}$ Embrapa Rondônia, BR 364, km 5,5, 76800-815 Porto Velho, RO, Brazil \\ ${ }^{2}$ Embrapa Pecuária Sudeste, Rodovia Washington Luiz, km 234, 13560-970 São Carlos, SP, Brazil
}

Correspondence should be addressed to Luciana G. Brito, luciana@cpafro.embrapa.br

Received 8 November 2010; Revised 12 January 2011; Accepted 28 January 2011

Academic Editor: Guillermo Virkel

Copyright (C) 2011 Luciana G. Brito et al. This is an open access article distributed under the Creative Commons Attribution License, which permits unrestricted use, distribution, and reproduction in any medium, provided the original work is properly cited.

\begin{abstract}
The adult immersion test (AIT) was used to evaluate the efficacy of acaricide molecules used for control of Rhipicephalus microplus on 106 populations collected in five municipalities in the state of Rondônia in the Brazilian South Occidental Amazon region. The analysis of the data showed that the acaricide formulations had different efficacies on the tick populations surveyed. The synthetic pyrethroids (SPs) acaricides were the least effective (48.35-76.84\%), followed by SP + organophosphate (OP) associations (68.91$81.47 \%)$ and amidine (51.35-100\%). For the macrocyclic lactones (MLs), the milbemycin (94.84-100\%) was the most effective, followed by spinosad (93.21-100\%) and the avermectins (81.34-100\%). The phenylpyrazole (PZ) group had similar efficacy (99.90\%) to the MLs. Therefore, SP acaricides, including associations with OP, and formulations based on amidine presented low in vitro efficacy to control the $R$. microplus populations surveyed.
\end{abstract}

\section{Introduction}

Brazil is the world's sixth leading producer of milk [1], and dairy farming is an important source of income for small producers as well as of industrial jobs in Brazil and in Rondônia state, a new Brazilian frontier for dairy farming that accounts for $95 \%$ of milk production in this region [2].

Most dairy herds in the Brazilian Southwestern Amazon are crossbreeds (Bos Taurus $\times$ Bos indicus) with varying bloodline degrees. However, the incorporation of crossbreeds with greater percentages of taurine breeds specialized for milk production, such as Holsteins, has made dairy herds more susceptible to infestation by ticks [3]. The climate conditions in the region are propitious for the establishment of cattle ticks due to the predominantly equatorial climate, characterized by average annual rainfall of $2,500 \mathrm{~mm}$ and average annual temperature of $24^{\circ} \mathrm{C}$, with well-defined wet and dry seasons [4].
Besides transmitting diseases, $R$. microplus impairs milk production because each female tick is able to ingest $1.0 \mathrm{~mL}$ of blood from the host cow during its parasite phase, causing a weight loss of approximately $1 \mathrm{~g}$ and reducing milk production by $8.9 \mathrm{~mL}$. In economic terms, these ticks cost farmers around US\$ 7.30/head/year when considering the production losses and treatment costs [57].

Despite the disadvantages of using acaricides, such as environmental contamination, potentially harmful residues in meat and milk, and toxicity to workers who apply them, these drugs are still essential to control tick infestations in the world [8]. However, the intensive use of chemical formulations leads to loss of efficacy of the base molecules because of the development of resistant tick populations. The spread of this resistance reveals the limits on chemical control of this parasite, making it essential to administer these chemicals wisely [6]. 
There are reports in the literature of growing resistance of cattle ticks to chemical molecules in many countries including Brazil, but the status is unknown of pesticide resistance in cattle tick populations in the Southwestern Amazon [6, 912].

Many dairy farmers in the state of Rondônia have reported the failure of tick control programs in their herds and have requested assistance in choosing more effective pesticides, which was the purpose of the present study.

\section{Materials and Methods}

2.1. Characterization of Area and Sites of Collecting the Tick Samples. Between March 2007 and October 2009, engorged female ticks were collected from 106 dairy farms. The herds were formed of crossbreed animals of Holstein (Bos taurus) and dairy Gir (Bos indicus), with bloodline degrees varying from $1 / 2$ to $5 / 8$. The herd size at most of farms ranged from 18 to 42 animals, though one farm had 116 animals.

The herds came from dairy farms in the municipalities of Jarú, Ouro Preto do Oeste, Ji-Paraná, Presidente Médici, and Rolim de Moura (Figure 1), all located between $10^{\circ} 26^{\prime}$ and $11^{\circ} 43^{\prime}$ South Latitudes and $62^{\circ} 27^{\prime}$ and $61^{\circ} 54^{\prime}$ West Longitudes. The predominant climate in the region according to the Köppen classification is a megathermal, with the dry season occurring in winter [13].

Dairy farmers responsible for each of the herds evaluated were invited to respond to a questionnaire regarding the use of acaricides, containing questions on the types used, frequency of treatments, and application method.

2.2. Collection and Preparation of Ticks. In each farm, up to 250 engorged female $R$. microplus ticks with a length equal to or greater than $4 \mathrm{~mm}$ were collected from cows naturally infected, none of which had received tick treatments for at least 30 days. The ticks were placed in identified plastic flasks free of acaricide residues with lids containing small holes, which were transported to the Embrapa Rondônia Animal Health Laboratory within 36 hours of collection for the evaluation of the in vitro efficacy of acaricides through the adult immersion test (AIT). Only samples in which no oviposition was observed were analyzed.

In the laboratory, all females were separated, carefully washed, and then dried on absorbent paper. Engorged females weighing between 160 and $300 \mathrm{mg}$, with no signs of injury, were used in the tests.

2.3. Acaricides. Technical fipronil was provided by Merial and stored at room temperature and was used at a final concentration of $0.0001 \%$. The following commercial acaricides were purchased and stored at $4{ }^{\circ} \mathrm{C}$; Triatox ectoparasiticide (12.5\% amitraz, Intervet Schering-Plough Animal Health), diluted with distilled water to a final concentration of $0.00006 \%$; Flytick ectoparasiticide (15\% cypermethrin, Vallé), at a final concentration of $0.00015 \%$; Alatox ectoparasiticide $(5 \%$ cypermethrin $+45 \%$ dichlorvos, Fort Dodge Animal Health), at final concentrations of $0.00005 \%$ and $0.00045 \%$, respectively, Colosso ectoparasiticide (15\% cypermethrin $+25 \%$ dichlorvos $+1 \%$ citronellal, Ouro Fino Animal Health), at final concentrations of $0.00015 \%$, $0.00025 \%$, and $0.00001 \%$, respectively, Butox ectoparasiticide $50 \%$ deltamethrin, Intervet Schering-Plough Animal Health), at a final concentration of $0.0005 \%$; Dectomax injectable endectocide for cattle (doramectin $10 \mathrm{mg} / \mathrm{mL}$, Pfizer Animal Health), Ivomec injection for cattle (ivermectin $10 \mathrm{mg} / \mathrm{mL}$, Merial); Baymec injectable endectocide (abamectin $10 \mathrm{mg} / \mathrm{mL}$, Bayer Health Care); Elector ectoparasiticide (2.46\% spinosad, Elanco) and Cydectin (moxidectin $10 \mathrm{mg} / \mathrm{mL}$, Fort Dodge Animal Health), all at a final concentration of $0.0001 \%$.

2.4. Adult Immersion Tests. The AIT conducted followed the method described by Drummond et al. [14]. Each group of 10 females was immersed for 10 minutes in $30 \mathrm{~mL}$ of the acaricide solutions. Commercial formulations of amitraz; cypermethrin; cypermethrin + dichlovos; cypermethrin + dichlovos + citronellal; deltamethrin; spinosad were diluted in distilled water according to the label recommendations.

For the evaluation of the avermectins (ivermectin, doramectin, and abamectin) and milbemycin (moxidectin), the females were immersed for 30 minutes in $30 \mathrm{~mL}$ of the solutions prepared according to the method proposed by Sabatini et al. [15]. To prepare the $1 \%$ fipronil solutions, $625 \mathrm{mg}$ of technical fipronil dissolved in $80 \mathrm{~mL}$ of PA acetone was used, diluted in $120 \mathrm{~mL}$ of sterile distilled water.

All solutions described were kept under constant agitation during the immersion period. Because of the large number of engorged females, only the control was prepared in triplicate, and the field populations were analyzed with two replicates. Each replicate was performed with ten $R$. microplus females with weights as homogenous as possible. The females of the control groups were immersed in distilled water for 30 minutes.

After immersion in the pesticide solutions or distilled water, all the engorged females were fixed with two-sided adhesive tape in Petridishes ( $90 \mathrm{~mm}$ diameter), which were identified by group, weight, pesticide, and testing date. The Petridishes containing the engorged females were incubated in a climate-controlled chamber at $27 \pm 1^{\circ} \mathrm{C}$ and relative humidity of $85 \pm 5 \%$. After the oviposition period (1418 days), the eggs were weighed and transferred to test tubes $(150 \mathrm{~mm}$ in height $\times 15 \mathrm{~mm}$ in diameter closed with cotton balls). The identified tubes were placed in the climate-controlled chamber under the same temperature and relative humidity conditions described previously, where they remained until the larvae hatched.

The hatching rate of the R. microplus larvae was based on visual estimation of the percentage of unhatched eggs remaining and of egg shells from which larvae had hatched.

The effectiveness of the acaricides was determined by the effect on the estimated reproduction (ER) of the engorged females in a treatment group. The percentage control (\% control) of ER afforded by the acaricides was determined by comparing the total ER of all treatment groups with that of the control group according to Drummond et al. [14], calculated with the following formulas. 


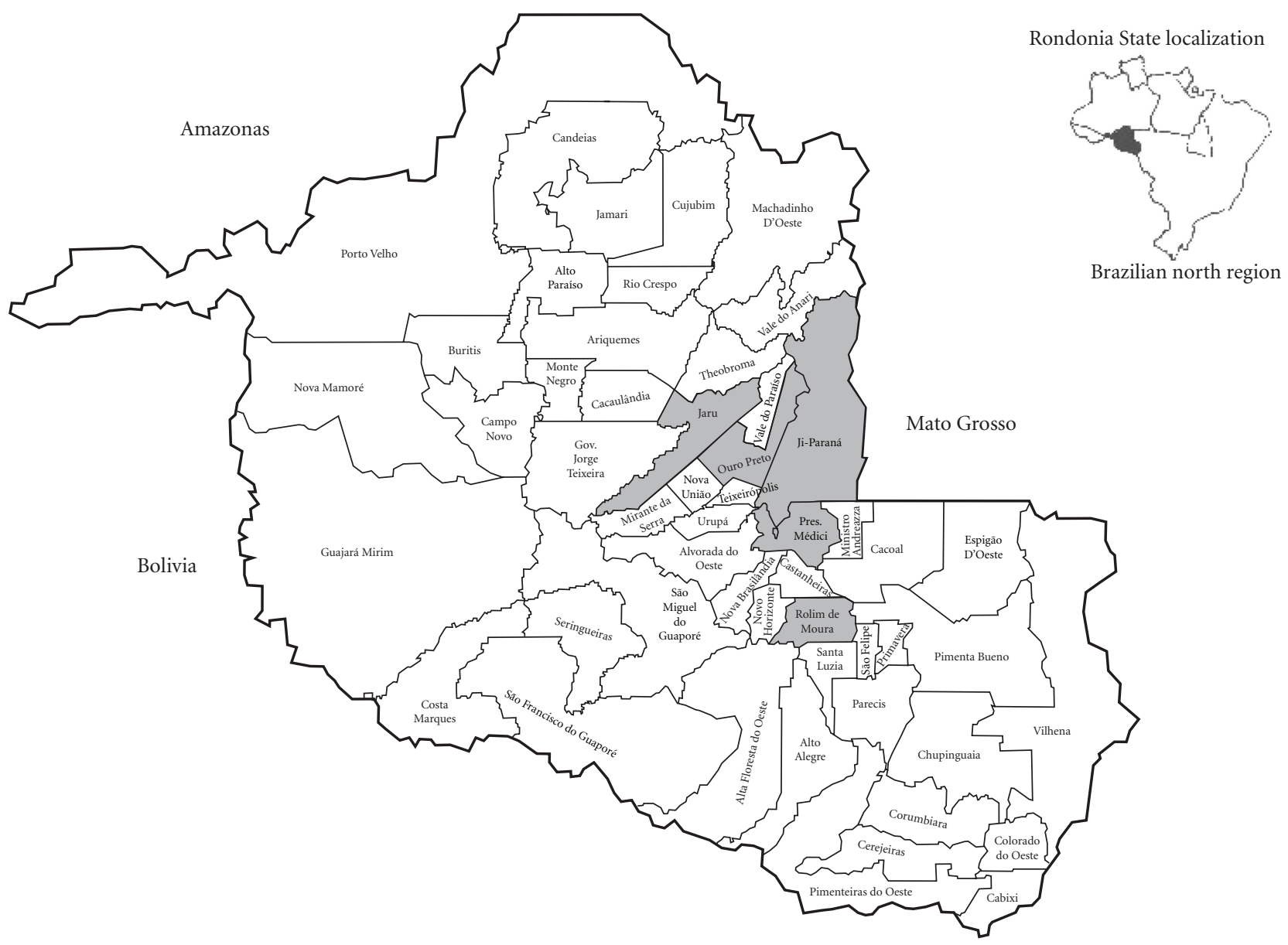

FIGURE 1: Location of the municipalities in the state of Rondônia where the populations of Rhipicephalus microplus were evaluated for efficacy of the acaricides.

$$
\mathrm{ER}=\frac{\text { Egg weight }}{\text { Engorged female weight }} \times \% \text { hatched } \times 20,000^{*} .
$$

*Estimated numbers of eggs in $1 \mathrm{~g}$ of Rhipicephalus microplus eggs

$$
\% \text { control }=1-\frac{\text { ER of pesticide group }}{\text { ER of control group }} \times 100 .
$$

R. microplus populations presenting a control percentage greater than or equal to $95 \%$ to the acaricide were considered susceptible. In vitro efficacy of $95 \%$ is the threshold for the approval of an acaricide product in Brazil according to federal regulations [16].

2.5. Statistical Analysis. For the interpretation of the results, the acaricide factor was analyzed in order to quantify the effect of the location (municipality) and of a specific acaricide, along with the effect of the interaction of both effects. The model's estimates were obtained by employing the PROC GLM routine of the Statistical Application System (SAS) (SAS version 8.2; SAS Institute, Inc., Cary, NC) considering the arcsine of the square root of the mortality percentages. In the absence of an interaction, multiple comparison between the marginal means of the acaricide factor was carried out using the Tukey-Kramer test, which is adequate for factor analysis with a different number of repetitions. The estimates of the confidence interval of the mean were interpreted as a measure of reliability of using the acaricide bases in the region.

\section{Results}

Through the responses of farmers, it could be observed that SP acaricides were used in most of the properties (87.3\%). Substitution of acaricide bases did not occur in systematic form in all farms, and when it occurred, the reason given was mainly price and ease of purchase of the acaricides in the local market. The frequency of treatments to control the cattle ticks was weekly in $43.7 \%$ of the farms, and the method of acaricide application most often used was spraying on the animals with manual backpack pumps.

The mean efficacy of the acaricides and their respective standard deviations against $R$. microplus collected from dairy 
TABLE 1: Efficacy of different acaricide bases on populations of Rhipicephalus microplus collected from dairy herds in the state of Rondônia, Brazil.

\begin{tabular}{|c|c|c|c|}
\hline $\begin{array}{l}\text { Chemical group } \\
\text { of function }\end{array}$ & $\begin{array}{c}\text { Min. efficacy } \\
(\%)\end{array}$ & $\begin{array}{c}\text { Max. efficacy } \\
(\%)\end{array}$ & $\begin{array}{c}\text { Mean efficacy } \\
(\% \pm \mathrm{SD})\end{array}$ \\
\hline Amidin & 51.35 & 100 & $77.20 \pm 15.53$ \\
\hline Cypermethrin & 48.35 & 70.5 & $61.23 \pm 6.83$ \\
\hline Deltamethrin & 61.22 & 76.84 & $67.10 \pm 4.70$ \\
\hline $\begin{array}{l}\text { Cypermethrin + } \\
\text { dichlorvos }\end{array}$ & 68.91 & 81.47 & $74.08 \pm 4.10$ \\
\hline $\begin{array}{l}\text { Cypermethrin + } \\
\text { chlorpyrifos + } \\
\text { citronellal }\end{array}$ & 72.41 & 86.37 & $78.08 \pm 4.10$ \\
\hline Doramectin & 86.21 & 100 & $99.74 \pm 1.43$ \\
\hline Ivermectin & 86.84 & 100 & $97.61 \pm 4.29$ \\
\hline Abamectin & 81.34 & 100 & $99.65 \pm 2.22$ \\
\hline Milbemycin & 94.84 & 100 & $99.94 \pm 0.51$ \\
\hline Spinosin & 93.21 & 100 & $99.96 \pm 0.23$ \\
\hline Phenylpyrazole & 92.78 & 100 & $99.90 \pm 0.74$ \\
\hline
\end{tabular}

herds in Rondônia are presented in Table 1. Avermectins, milbemycin, PZ, and spinosin presented the highest mean efficacies according to the AIT.

Acaricide formulations containing cypermethrin and deltamethrin presented the lowest efficacy levels observed in the AIT, while the associations of SP + OP and SP + OP + citronellal presented intermediate efficacy in comparison with the other acaricides evaluated. The products based on amidin were more effective than the SP, but with a higher confidence interval. The data obtained suggest that citronellal enhanced the efficacy of the SP + OP association. The macrocyclic lactones (MLs) group, the spinosins, and milbemycin showed high efficacy according to the AIT, as well as the PZ, all with a small confidence interval (Figure 2). Ivermectin, abamectin, and doramectin had lost efficacy on some farms, as shown by minimum efficacy values between 81 and $86 \%$.

The variance analysis showed that the acaricides had variable efficacy, according to the $F$-test at $1 \%$ significance (Table 2). Nonsignificant effects of the location $(L)$ and of the acaricide with location interaction $(A \times L)$ indicates that the effectiveness of a specific acaricide did not differ among the municipalities, as the interaction coefficient was low $(7.05 \%)$.

\section{Discussion}

Presently, the Working Group on Parasite Resistance (WGPR-FAO) recommends the AIT proposed by Drummond et al. [14] for the evaluation of the susceptibility to acaricides in cattle tick populations, since it is fast, simple and a relatively cheap method for the detection of acaricide resistance in the field [6]. Despite the high variation of AIT results obtained for SP, OP, amitraz and moxidectin as observed by Jonsson et al. [17], the AIT is a valuable tool for the rapid and cheap detection of loss of susceptibility

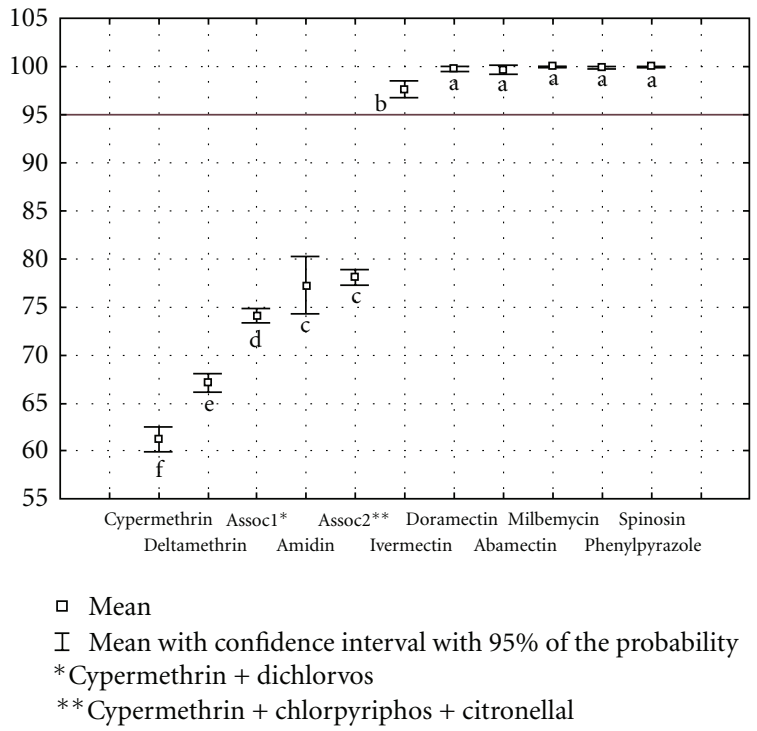

Figure 2: Effectiveness of acaricide bases observed in adult immersion test (AIT) in Rhipicephalus microplus populations surveyed in Rondônia state, Brazil. * Means followed by the same letter do not differ according to the Tukey-Kramer test at 1\% significance. The bar indicates the $95 \%$ minimum efficacy set by Brazilian federal regulations for the marketing of acaricides.

TABLE 2: Analysis of variance of the effects of the location $(L)$ and of the acaricides $(A)$ on the susceptibility to acaricides in Rhipicephalus microplus populations collected in the state of Rondônia, Brazil.

\begin{tabular}{lcccc}
\hline Source of variation & D.F. & S.S. (Type III) & M.S. & $F$ \\
\hline Acaricide $(A)$ & 10 & 71.2554 & 7.1257 & $834.55^{* *}$ \\
Location $(L)$ & 4 & 0.0252 & 0.0063 & $0.74^{\text {ns }}$ \\
$A \times L$ & 40 & 0.3341 & 0.0084 & $0.98^{\text {ns }}$
\end{tabular}

Coefficient of variation 7.05

D.F.: Degrees of freedom; S.S. (Type III): Type III sum of squares; M.S.: Mean square error; F: F-test estimates; ${ }^{* *}$ : Significant at $1 \%$ probability; ${ }^{\text {ns: }}$ Not significant.

to a certain acaricide and should be used with this specific objective in resistance management programs.

According to the analysis of variance, there were no differences of susceptibility to a specific acaricide among the different municipalities, which demonstrates that the acaricides evaluated presented similar efficacy against the different $R$. microplus populations evaluated.

The efficacies of cypermethrin and deltamethrin on the R. microplus populations studied varied from $48.33 \%$ to $70.5 \%$ and $61.22 \%$ to $76.84 \%$, respectively. These efficacy levels differ from those found in other regions of Brazil. Pereira [11], in the state of São Paulo, observed efficacy of $25.39 \%$ for deltamethrin and $31.10 \%$ for cypermethrin, while Furlong et al. [12], in Minas Gerais, reported averages of $15.3 \%$ for deltamethrin and $9.1 \%$ for cypermethrin. The differences in efficacy of these acaricies observed between the different Brazilian states can be related to the way they are used, such as inadequate spraying, underdosage or 
overdosage [18], and/or high frequency of use causing the development of resistant populations [19].

The occurrence of synergism in acaricide formulations containing SP and OP was observed by Landim et al. [10]. They investigated tick populations collected in the region of Uberaba (Minas Gerais) and observed that the formulations containing this combination were more effective than formulations containing SP or OP alone. The authors reported that SP and OP used separately had maximum efficacy levels of $43.6 \%$ and $46.7 \%$, respectively, while the $\mathrm{SP}+\mathrm{OP}$ associations showed efficacy between 75.5 and $97.7 \%$. This result was also observed by Furlong et al. [12], who reported a small increase in efficacy of acaricides containing a combination of $\mathrm{SP}$ and $\mathrm{OP}$ on $R$. microplus populations from the states of Minas Gerais, Rio de Janeiro and São Paulo. However, in the present study we did not observe any significant increase in efficacy of the SP + OP formulations compared with those containing only SP against tick populations from Rondônia.

Furlong et al. [12] also evaluated the efficacy of a formulation containing SP + OP + citronellal, which demonstrated mean efficacy of $74.1 \%$, close to its mean efficacy observed against cattle tick populations in the present study.

The mean efficacy of the acaricide formulations containing SP, SP + OP and SP + OP + citronellal can be considered unsatisfactory for the control of $R$. microplus in the surveyed farms, considering $95 \%$ as the minimum efficacy for approval of an acaricide according Brazilian federal regulations [16].

Several Brazilian authors have studied the efficacy of amitraz on $R$. microplus populations using the AIT. The results have shown different susceptibility levels. In the Southeast region, Mendes et al. [9] evaluated ticks from 17 ranches from the state of São Paulo and reported an average efficacy of $77.44 \%$, similar to our results (77.2\%). Furlong et al. [12] evaluated the susceptibility to amitraz on $196 R$. microplus populations from the states of Minas Gerais, Rio de Janeiro, São Paulo and Goiás and found $47.9 \%$. In the Northeast region, low efficacy of amitraz was reported in the states of Pernambuco $(40.5 \%)$ by Santana [20] and Bahia (30.95\%) by Campos Junior and Oliveira [21]. Nevertheless, in the South region, satisfactory results were obtained in the state of Paraná by Souza et al. [22], where the mean efficacy of amitraz was above $95 \%$ for all 17 R. microplus populations tested. Camilo et al. [23], evaluating the susceptibility of 20 cattle tick populations in the state of Rio Grande do Sul, observed the presence of resistance or low efficacy in the majority of populations analyzed.

The low efficacy observed for SP, OP and amitraz in the studied area can be associated to the development of resistance to these molecules in local populations of $R$. microplus in the state of Rondônia. Possibly the inadequate use of these acaricides at the farms studied, such as application of sub-lethal doses, sequential use of the same chemical group for long periods and short intervals between treatments, has favored the development of resistance [24]. Since 1999 the Rondônia government has had a policy [25] of providing resources to local dairy farmers to encourage them to genetically improve their herds using European breeds
(Holstein) as crosses. This initiative has been resulting in significant gains in productivity. However, Bos taurus breeds incorporated to increase milk production may also have favored infestations of $R$. microplus. In general, producers tend to reduce the interval between treatments in persistent and heavy tick burdens rather than trying new treatment strategies, thus favoring the development of resistant populations of R. microplus.

With respect to the MLs, ivermectin, doramectin and abamectin presented efficacies $<95 \%$ in some cases. However, these compounds are not recommended for use on lactating cows, since they leave residues in the milk. However, these compounds can be used on other categories of herds to reduce the non-parasitic instars in pastures as part of an integrated management program, as observed by Castro [8].

The spinosins are indicated for use on lactating cows and demonstrated excellent efficacy on the tick populations assessed, proving to be a potentially good acaricide to control ticks in the studied area.

The PZ group also was highly efficient to control the cattle tick populations evaluated. This efficacy $(99.90 \%)$ is higher than that reported by Furlong et al. [12] (88.5\%) in tests on 723 R. microplus populations from various Brazilian states.

The analysis of the susceptibility to different acaricides with $R$. microplus populations from dairy farms in the state of Rondônia contributes to the rational and strategic use of acaricides in that area, which is responsible for about $85 \%$ of milk production in the Southwestern Amazon. The adequate use of efficient acaricide molecules associated with integrated management practices to control cattle ticks can contribute to the sustainability of dairy farm operations in the region. Such measures are important to delay the development of resistant $R$. microplus populations.

\section{Acknowledgments}

The study received financial support from National Council for Scientific and Technological Development (CNPq, Process no. 554110/2005-9) and the Rondônia Dairy Sector Chamber (Proleite) for funding. The authors also thank Antonio Xavier do Nascimento of the Embrapa Rondônia Animal Health Laboratory for his valuable assistance in conducting the laboratory tests.

\section{References}

[1] USDA, "Dairy World Markets and Trade," Circular Series, 2008, http://www.fas.usda.gov/dlp/circular/2008/DairyCir_Final_Dec08_PSD.pdf.

[2] IBGE, "Municipal Livestock Research," 2009, www.ibge.gov .br/home/estatistica/economia/ppm/2009/default.shtm.

[3] N. N. Jonsson, A. L. Matschoss, P. Pepper, P. E. Green, and J. Ansell, "Resistance of Holstein-Friesian cows to infestation by the cattle tick (Boophilus microplus)," Veterinary Parasitology, vol. 89, no. 4, pp. 297-305, 2000.

[4] G. Fisch, J. A. Marengo, and C. A. Nobre, "A general review on the Amazon climate," Acta Amazonica, vol. 28, no. 2, pp. 101-126, 1998. 
[5] N. N. Jonsson, D. G. Mayer, A. L. Matschoss, P. E. Green, and J. Ansell, "Production effects of cattle tick (Boophilus microplus) infestation of high yielding dairy cows," Veterinary Parasitology, vol. 78, no. 1, pp. 65-77, 1998.

[6] FAO, "Acaricide resistance: diagnosis, management and prevention," in Guidelines Resistance Management and Integrated Parasite Control in Ruminants, pp. 25-77, Animal Production and Health Division, Agriculture Department, Food and Agriculture Organization of the United Nations, Rome, Italy, 2004.

[7] N. N. Jonsson, "The productivity effects of cattle tick (Boophilus microplus) infestation on cattle, with particular reference to Bos indicus cattle and their crosses," Veterinary Parasitology, vol. 137, no. 1-2, pp. 1-10, 2006.

[8] J. J. De Castro, "Sustainable tick and tickborne disease control in livestock improvement in developing countries," Veterinary Parasitology, vol. 71, no. 2-3, pp. 77-97, 1997.

[9] M. C. Mendes, C. J. Verissimo, C. N. Kaneto et al., "Bioassays for measuring the acaricides susceptibility of cattle tick Boophilus microplus (Canestrini, 1887) in São Paulo state, Brazil," Journal of Animal, Plant Sanity and Environmental Protection, vol. 68, no. 2, pp. 23-27, 2001.

[10] V. J. C. Landim, E. A. Silva, J. M. V. Paes et al., "Diagnosis of the situation of resistance to acaricides in Boophilus microplus in beef and dairy cattle in the Uberaba region," FAZU Journal, vol. 3, no. 1, pp. 63-69, 2006.

[11] J. R. Pereira, "In vitro efficacy of comercial formulations of ixocidides in engorged female of Boophilus microplus collected of dairy cattle at Paraíba Valey in the state of São Paulo," Brazilian Journal of Veterinary Parasitology, vol. 15, no. 2, pp. 45-48, 2006.

[12] J. Furlong, J. R. Martins, and M. C. A. Prata, "The tick of cattle and resistance: we have to celebrate?" A Hora Veterinária, vol. 27, pp. 1-7, 2007.

[13] M. J. G. Silva, "Climatology of Rondônia state," Secretaria de Estado do Desenvolvimento Ambiental, Porto Velho, Rondônia, Brazil, 2010, http://www.sedam.ro.gov.br/index.php/meterologia/climatologia.html.

[14] R. O. Drummond, S. E. Ernst, J. L. Trevino, W. J. Gladney, and O. H. Graham, "Boophilus annulatus and B. microplus: laboratory tests of insecticides," Journal of Economic Entomology, vol. 66, no. 1, pp. 130-133, 1973.

[15] G. A. Sabatini, D. H. Kemp, S. Hughes, A. Nari, and J. Hansen, "Tests to determine $\mathrm{LC}_{50}$ and discriminating doses for macrocyclic lactones against the cattle tick, Boophilus microplus," Veterinary Parasitology, vol. 95, no. 1, pp. 53-62, 2001.

[16] Brazil, Ministry of Agriculture, Livestock and Food Supply, "Ordinance No. 48, Technical Regulation for licensing and license renewal of antiparasitic products for veterinary use," Diário Oficial, no. 92, Section 1, 1997.

[17] N. N. Jonsson, R. J. Miller, and J. L. Robertson, "Critical evaluation of the modified-adult immersion test with discriminating dose bioassay for Boophilus microplus using American and Australian isolates," Veterinary Parasitology, vol. 146, no. 3-4, pp. 307-315, 2007.

[18] M. W. Bianchi, N. Barré, and S. Messad, "Factors related to cattle infestation level and resistance to acaricides in Boophilus microplus tick populations in New Caledonia," Veterinary Parasitology, vol. 112, no. 1-2, pp. 75-89, 2003.

[19] J. Furlong and J. R. S. Martins, "Resistência dos carrapatos aos carrapaticidas," Juiz de Fora: CNPGL-EMBRAPA, (Boletim Técnico 59), 2000.

[20] V. L. A. Santana, "Situation of chemical control of Boophilus microplus (Canestrini, 1887) the sub-regions in the area of forest and wasteland in the state of Pernambuco, based on in vitro efficacy of acaricides in engorged females. Dissertation in Veterinary Science," Federal Rural University of Pernambuco, Recife, Pernambuco, Brazil, 2000.

[21] D. A. Campos Jr. and P. R. Oliveira, "In vitro valuation of acaricides efficiency to Boophilus microplus (Canestrini, 1887) (Acari: Ixodidae) from bovines at the region of Ilhéus, Bahia, Brazil," Ciência Rural, vol. 35, no. 6, pp. 1386-1392, 2005.

[22] A. P. Souza, A. A. Sartor, V. Bellato et al., "Efficacy of acaricides in dairy cattle herds in southern region of Parana state, Brazil," Journal of Agronomy and Veterinary Sciences, vol. 2, no. 1, pp. 131-135, 2003.

[23] G. Camillo, F. F. Vogel, L. A. Sangioni, G. C. Cadore, and R. Ferrari, "In vitro evaluation of acaricides efficiency to bovine's ticks of Rio Grande do Sul State, Brazil," Ciência Rural, vol. 39, no. 2, pp. 490-495, 2009.

[24] M. C. L. Silva, R. Neves Sobrinho, and G. F. C. Linhares, "In vitro evaluation of effectiveness of chlorfenvinphos and cyhalothrin for the control of Boophilus microplus (Canestrini, 1887) in dairy farms of the microregion of Goiânia-Goiás," Brazilian Animal Science, vol. 1, no. 2, pp. 143-148, 2000.

[25] SEAPES, "Relatório anual de 2007," Secretaria de Estado da Agricultura e do Desenvolvimento Econômico e Social. Governo de Rondônia. Porto Velho: SEAPES/RO, 2007. 

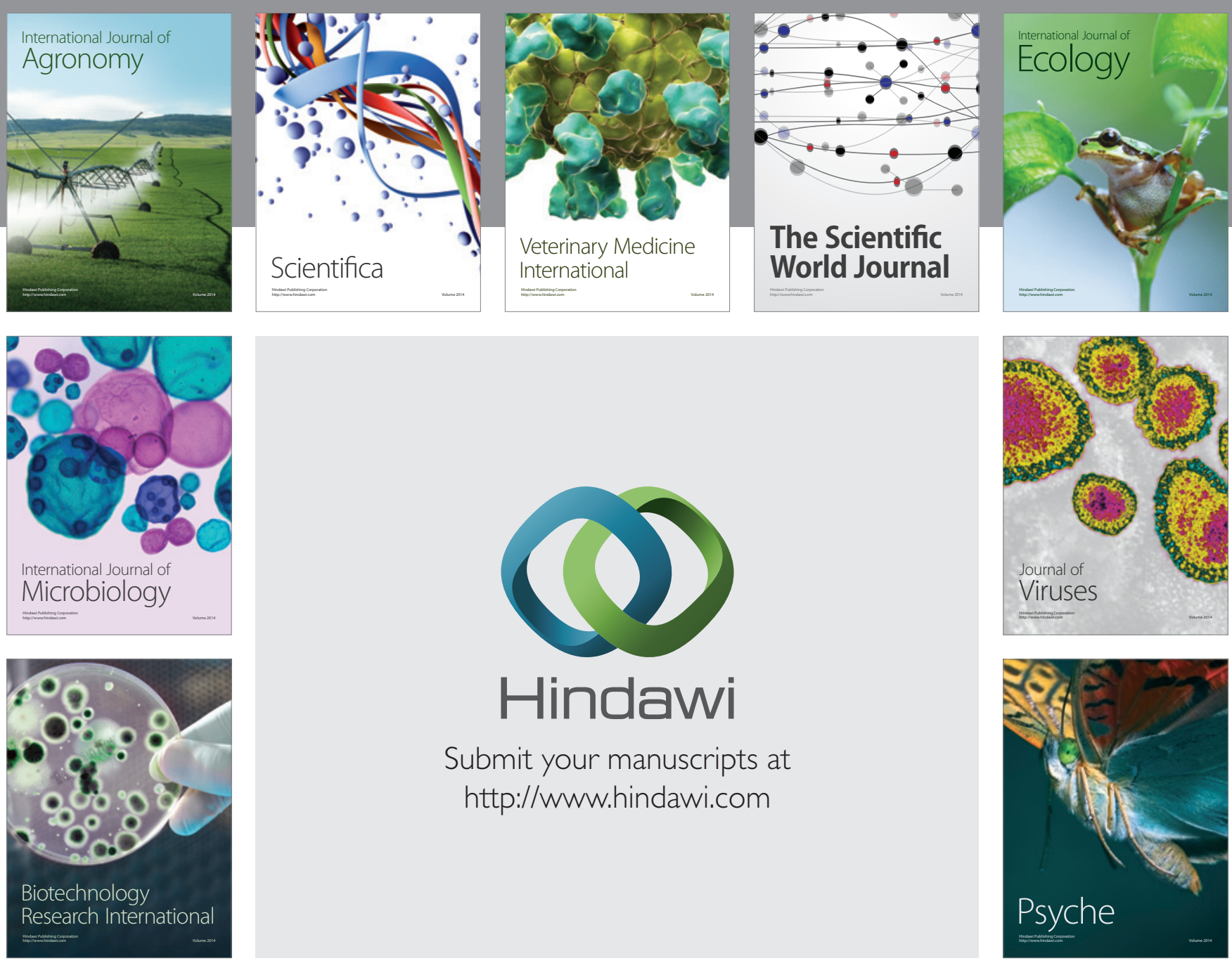

Submit your manuscripts at

http://www.hindawi.com
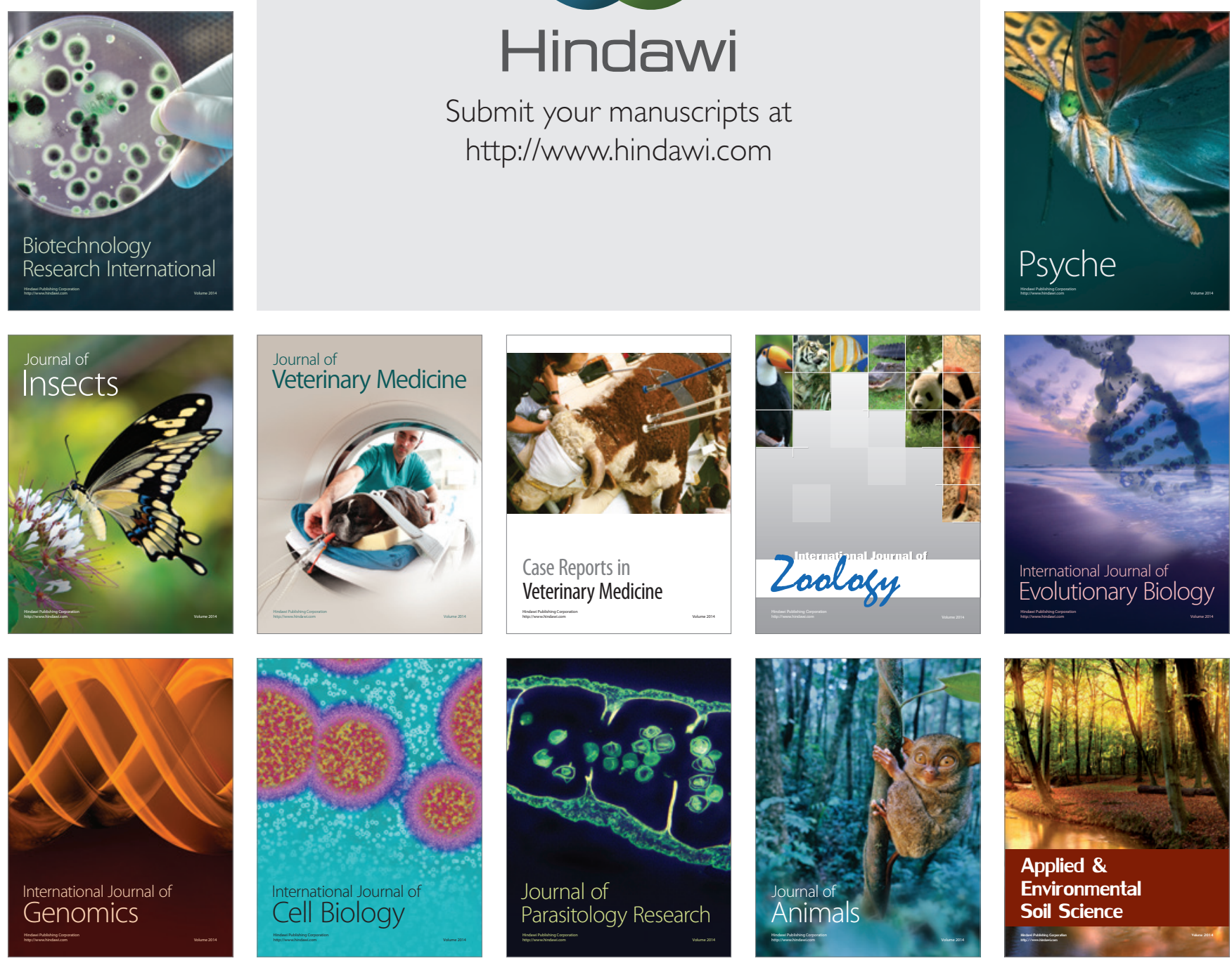